\title{
Project Management as a Technology for Managing a Modern Educational Organization
}

\author{
Lyudmila Podymova ${ }^{1^{*}}$, Marina Khmelkova $^{2,3}$, Maria Semyonova ${ }^{4,5}$, Tatyana \\ Golovyatenko ${ }^{5}$, and Maria Poliakova ${ }^{5}$ \\ ${ }^{1}$ Moscow Pedagogical State University, Department of Educational Psychology, Faculty of Pedagogy \\ and Psychology, Moscow, Russia \\ ${ }^{2}$ Russian New University, Institute of Psychology and Pedagogics, Department of General \\ Psychology and Labor Psychology, Moscow, Russia \\ ${ }^{3}$ State budgetary educational institution of Moscow "School № 64", Moscow, Russia \\ ${ }^{4}$ Moscow City University, Institute of Culture and Arts, Moscow, Russia \\ ${ }^{5}$ Russian New University, Institute of Psychology and Pedagogics, Department of Pedagogical \\ Education, Moscow, Russia
}

\begin{abstract}
The main goal of the article is to describe project management used in education. The concept of "project management" and its main components in the conditions of educational organizations as a system mechanism in resource management have been theoretically analyzed. The role of investments and state support for training and education on project management not only in the national but also foreign education has been shown. The main goals and areas of the implementation in the educational sector have been revealed through the example of the Education national project. The role of the methodology for network planning of the employees' activities in an organization has been considered. This creates guidelines for organizing the research on optimizing human resources in the organization and improving their efficiency. The article has focused on one of the approaches in project management, namely, the projective-resource one, where the head of the educational organization plays an important role both in project management and in the formation of a team for its implementation.
\end{abstract}

\section{Introduction}

Innovative processes and modernization of the educational system in all its subsystems and levels make modern leaders of educational organizations apply new approaches and technologies in their activities [1]. Despite the fact that the project approach in the educational system is not new, the issues related to the implementation of the leading principles of project management in the educational practice in the context of socio-economic changes have not been studied enough. This determined the goals and objectives of this study.

In the most common sense, the project management is interpreted as an activity (a set of functions, actions) on managing projects. Nowadays, there are several definitions of this concept. The attention is focused on the most common ones. The project management is [2-

\footnotetext{
* Corresponding author: pod 1s@mail.ru
} 
4] a special technology to fulfill managerial functions in ensuring the quality and efficiency of people's activities when solving certain tasks related to taking a set of measures, e.g., in various tactical and strategic areas within a common mission and top priority goal of the organization; the area of management that formed the basis for modern management of a wide range of organizations and social communities; the methodology for organizing, planning, managing, and coordinating human and material resources throughout the project life cycle aimed at the efficient achievement of its goals and results (in terms of composition, volume of works, cost, time, and quality) by applying a system of modern management methods, techniques, technologies, etc. N. Ewin, J. Luck, R. Chugh, and J. Jarvis define the main categories of problems that remain relevant in this area: commonness and difference (in using terms and applying methodology), the structure of the educational process, the practical relevance of the educational process, support of top management and stakeholders, as well as new trends in project management training, etc. [5].

In the context of the efficient activity and the development of educational organizations, the project management is considered as a systemic mechanism in resource management. The efficient use of resources for any organization is a condition for its sustainable development, competitiveness, and is a kind of indicator of competent management and the key to minimizing costs while striving to maximize meeting the consumer demand [4]. There are three components in each project: achieving a certain goal, search for nontrivial solutions and efforts, and a clear time limit. The project results in a new (unique) product or service $[2]$.

In the Russian Federation, the education sector is a top priority. Success in not only the socio-economic and political, but also international areas is associated with success in the educational system. The priority of this area is reflected in the primary solution of material and financial problems of the educational system. Based on the analysis made by E.V. Savenkova, in the modern education, the project management is used on a variety of levels from the federal government in the educational system to the pedagogical management in the "teacher-learners" system [4]. Thus, one of the leading and top priority projects implemented in the national education is the Education National Project [6]. This project is an initiative aimed at achieving two key objectives: 1) ensuring the global competitiveness of the Russian education and entering top 10 countries of the world in terms of the quality of general education, 2) upbringing a harmoniously developed and socially responsible individual on the basis of the spiritual and moral values of the peoples living in the Russian Federation, as well as historical and national-cultural traditions. These are the objectives of the national project: 1) for Russia to enter the top 10 countries of the world in terms of the quality of general education, 2) to create conditions for upbringing a harmoniously developed and socially responsible individual, 3 ) to focus the updated educational system on a child and his interests, 4) to fully digitalize schools, 5) to take care about teachers and their continuous professional growth, 6) online courses, robots and tablets will become the teacher's assistant rather than will replace the one, and 7) digitalization is an instrument of new educational opportunities. The term of the project is $01.01 .2019-31.12 .2024$, with the total budget of RUB 784.5 bln. The main sources of financing include the federal budget of the Russian Federation (RUB $723.3 \mathrm{bln}$ ), the budgets of the constituent entities of the Russian Federation (RUB $45.7 \mathrm{bln}$ ), and extrabudgetary funds (RUB $15.4 \mathrm{bln}$ ). The budget is distributed among ten federal projects included in the national project: Modern School, Every Child's Success, Support for Families Having Children, Digital Educational Environment, Teacher of the Future, Young Professionals, New Opportunities for Everyone, Social Activity, Export of Education, and Social Elevators for Everyone. Such investments and support are important in training and education in project management not only in the national but also in foreign education [7]. 
Such large-scale projects aim at implementing in goals and principles of the federal, regional, and local politics related to education and socio-cultural life of society. The participation in implementing various national and state projects and programs that comply with the strategy on modernizing the national education is one of the factors of the educational organization's competitiveness.

S.I. Vershinin states that depending on how the goal of the project is related to the conditions of its achievement in the current educational environment, one of four alternative strategies for the projects implementation is selected [4]: penetration (creation or increasing of marketing events - advertising, organization rating), development of educational technologies (introduction of new technologies in order to improve the efficiency of the educational environment), development of the educational environment (the creation of new mechanisms for the interaction between subjects and educational programs by using the existing technologies), and diversification (the introduction of new technologies into the existing educational environment in order to improve the efficiency of its functioning, while creating new mechanisms for the interaction of subjects and educational programs in the educational environment).

According to O.G. Prikot and V.N. Vinogradov, in project management as a process of modeling the future, there are two main approaches: goal-normative (planned-programmed, impersonal) and projective-resource (personality-centered, motivational-personal) [8], where the latter is important in this process. Success and efficiency of any project is the result of the competent organization of the interaction between the subjects involved in its development and implementation [3].

The main factors required for the successful project activity include $[8,9]$ the participation of management in organizing or supporting the project activity (coordinated leadership on all levels of the education management: federal, regional, city, municipal government, certain educational institution, or other entities); the willingness of the teaching staff to participate in the project activity (the creation of conditions that motivate them to develop and master pedagogical innovations, providing an opportunity to show oneself on a certain side: scientific, professional, and public); the association of specialists and division of labor; the provision with resources: scientific, personnel (professional), financial, material and technical, informational, as well as the procedure and methods for their use; the extreme clarity of the project goal, the maturity of organizing the actions to manage the system, its development and decision-making within and beyond the system; taking into account specific features during the project (local characteristics and specifics of culture). Therefore, the key to the project success is the implementation management that takes into account these peculiarities.

\section{Methods}

The project management is based on the methodology for network planning of all employees' activities in the organization. Human resources play an important role in this process, which allows optimizing resources and improving their efficiency. The task of the project manager is to form a team of performers, inform them about the right direction, motivate, recognize their achievements, and encourage them [10-12]. Moreover, when managing a project, the manager's functions also include planning, control, analysis, decision-making, compiling and maintaining the project budget, organizing the implementation, monitoring, evaluation, reporting, examination, verification and acceptance, accounting, and administration [3].

\section{Results}


What does team implementation of the project provide its participants and the organization with, as a whole? E.V. Savenkova emphasizes the following advantages of the teamwork in the project management: high performance, professional and social development of everyone, development of new constructive ideas, high speed response in critical situations, better work with all subjects of the educational process, self-confidence and certainty about the team for each team member, stress reduction for all team members, and the improvement of the psychological situation and life quality in the workplace [4]. The main advantage for an individual arising from membership in a team is the ability to meet a wide range of needs: social (cooperation, support, etc.), the need in respect, safety, and certainty. The benefits for an organization include results, contribution to the solution of tasks, knowledge, reduction of prejudice, and involvement (inclusion) [10].

\section{Discussion}

In the context of the prospects of project management in the educational system, this approach is particularly important for all teachers' professional activities [4, 13]. Project teams are created when the organization is undergoing changes and special hopes are imposed on them as agents of these changes. The teamwork is an efficient instrument to overcome resistance to new ideas [10]. According to a number of authors, this process is based on the reflective pedagogy [14-16].

\section{Conclusion}

On the one hand, the project management in an educational organization is a methodological basis for establishing and supporting constructive relationships among all subjects involved in the process. On the other hand, this is a resource for the formation and improvement of managerial competencies both among teachers and learners, and their parents (legal representatives) $[1,4]$. The efficiency of the completed project is a category to compare the costs and results of the project as a whole and its individual participants [3]. Social significance is one of important types of the project management effect in education.

The educational process is a controlled phenomenon and the main factor determining its quality is the quality of management [4]. Managers may include leaders of educational organizations in case of national, state and federal projects, and teachers on the level of an organization of the educational process. When implementing any project, the consideration of all components (functional, strategic, innovative, and personnel) ensures not only the stability of the processes quality, the viability of the educational organization, but also the possibility of its efficient strategic development in the future; when mobilizing its internal resources, it will be able to adequately respond to external challenges.

\section{References}

1. T. Baumann, K. Mantay, A. Swanger, G. Saganski, S. Stepke, Procedia - Social and Behavioral Sciences 226, 243-251 (2016)

2. S.I. Vershinin, Project management in education, (Center for New Technologies, Moscow, 2017)

3. S.V. Ershov, Project management: lecture notes (NAFU, Arkhangelsk, 2014)

4. E.V. Savenkova, O.A. Shklyarova, Project management in an educational organization: study guide (MSPU, Moscow, 2019)

5. N. Ewin, J. Luck, R. Chugh, J. Jarvis, Procedia Computer Science 121, 503-510 (2017) 
6. The Ministry of Education of The Russian Federation. Available at: https://edu.gov.ru/national-project

7. J. Ramazani, G. Jergeas, International Journal of Project Management 33(1), 41-52 (2015)

8. O.G. Prikot, V.N. Vinogradov, Strategic development of educational systems and organizations based on project management: study guide (Operational Printing Department of the HSE, St. Petersburg, 2011)

9. A. Calderón, M. Ruiz, R. O'Connor, Computer Standards \& Interfaces 60, 80-92 (2018)

10. A.V. Zhutkin, Management and organizational problems of an effective team in project activities: Dis. ... cand. soc. sci. (Moscow, 2003)

11. T.A. Potsukova, E.V. Gorlanova, Implementation of the model of the education quality management system in educational institutions of the Novosibirsk Region: experience, problems, prospects: Scientific and methodological materials of participants in a regional project (Publishing House NIPKiPRO, Novosibirsk, 2016)

12. F. Cambi, Studi sulla Formazione 1, 141-146 (2019)

13. G. Franceschini, Studi sulla Formazione 2, 253-270 (2019)

14. S. Cicmil, H. Gaggiotti, International Journal of Project Management 36(1), 208-218 (2018)

15. N. Arruda Filho, B. Przybylowicz Beuter, The International Journal of Management Education 18(1), (2020)

16. J. Ramazani, G. Jergeas, International Journal of Project Management 33(1), 41-52 (2015) 